\title{
PELAKSANAAN KONSELING OBAT OLEH APOTEKER DI APOTEK KABUPATEN BADUNG
}

\author{
Ni Putu Ruscita Anggreni ${ }^{1 *}$, I Made Agus Gelgel Wirasuta ${ }^{1}$ \\ ${ }^{1}$ Program Studi Farmasi, Fakultas Matematika dan Ilmu Pengetahuan Alam, \\ Universitas Udayana \\ *E-mail: ruscitaanggreni@gmail.com
}

\begin{abstract}
ABSTRAK
Permenkes RI No. 73 Tahun 2016 menyebutkan bahwa konseling merupakan salah satu pelayanan kefarmasian di Apotek. Penelitian ini bertujuan untuk mengetahui pelaksanaan konseling obat oleh Apoteker kepada pasien di Apotek sesuai dengan Peraturan Menteri Kesehatan Nomor 73 Tahun 2016. Jenis penelitian ini bersifat non eksperimental dengan rancangan cross sectional. Dalam penelitian ini data diambil dengan menyebarkan kuesioner melalui Google Form. Pengisian google form oleh Apoteker Pengelola Apotek (APA) di kabupaten Badung. Data yang diperoleh dianalisis dan selanjutnya dibuat persentasenya. Berdasarkan data yang diperoleh, sebanyak $100 \%$ responden pernah melaksanakan konseling kepada pasien dengan rentang waktu yang bervariasi. Responden sudah melakukan konseling dalam rentang waktu 1-10 menit. Pada saat pemberian konseling, sebanyak 55,55\% responden mengaku bahwa terdapat hambatan dalam pemberian konseling seperti waktu, tempat, dan pengetahuan yang kurang. Pemberian informasi dalam pelaksanaan konseling yaitu cara penggunaan dan penyimanan obat (100\%), waktu penggunaan obat $(88,89 \%)$, dosis obat dan lama penggunaan obat $(77,78 \%)$, serta efek samping obat $(66,67 \%)$. Hal ini sudah cukup baik untuk meningkatkan kepatuhan pasien dalam mengonsumsi obat. Namun, pendokumentasian konseling dan pencatatan riwayat pasien masih belum efektif dalam pelaksanaannya karena berbagai faktor. Dari segi pengetahuan apoteker terkait perundang-undangan yang mengatur kinerja tenaga kefarmasian, sebanyak 88,89\% responden sudah mengetahui hal tersebut. Maka dari itu, diharapkan apoteker dapat melaksanakan tugasnya dengan baik sesuai dengan peraturan perundang-undangan.
\end{abstract}

Kata kunci: Konseling, Apoteker, Apotek

Republic of Indonesia Health Minister Regulation No. 73 of 2016 states that counseling is one of the pharmaceutical services at the Pharmacy. This study aims to determine the implementation of drug counseling by Pharmacists to patients in the Pharmacy in accordance with The Republic of Indonesia Health Minister Regulation No. 73 of 2016. This type of research is non-experimental with cross-sectional design. In this study, the data was taken using a questionnaire via Google Form. Fill out the google form by the pharmacists in Badung Regency. The data obtained were analyzed and then the percentage was made. Based on the data obtained, as many as $100 \%$ of respondents had counseled patients with varying time periods. Respondents had counseled within 1-10 minutes. When providing counseling, as many as $55.55 \%$ of respondents asked that there were those who needed help, such as lack of time, place and knowledge. Provision of information in the implementation of counseling, namely how to use and store drugs (100\%), time of drug use (88.89\%), drug dosage and duration of drug use (77.78\%), and drug side effects $(66.67 \%)$. This is good enough to increase patient approval for taking the drug. However, counseling documentation and recording patient documentation is still not effective in its implementation due to various factors. In terms of the pharmacist's knowledge regarding the laws governing the performance of pharmaceutical personnel, $88.89 \%$ of respondents already knew that. Therefore, it is expected that pharmacists can carry out their duties properly in accordance with statutory regulations.

Keywords: Counseling, Pharmacist, Pharmacy 


\section{PENDAHULUAN}

Farmasi forensik adalah "the application of science to law" yang artinya aplikasi atau pemanfaatan ilmu pengetahuan tertentu untuk penegakan hukum dan peradilan [1]. Farmasi forensik terlibat dalam pekerjaan professional yang berkaitan dengan proses peradilan, proses regulasi, dan sistem lembaga penegak hukum (criminal justice system). Farmasi forensik memiliki beberapa domain seperti farmasi klinik, aspek administratif dari farmasi, dan ilmu farmasetika dasar. Farmasis yang memiliki spesialisasi berkaitan dengan pengetahuan praktek kefarmasian dikatakan sebagai farmasis forensik. Keahlian atau spesialisasi tersebut meliputi farmakologi klinik, manajemen pengobatan, reaksi efek samping dari obat, evaluasi terhadap pasien, patient counseling, patient monitoring, sistem distribusi sediaan farmasi dan alat kesehatan, serta drug analysis [2]. Berdasarkan hal tersebut, peran Apoteker sebagai farmasi forensik juga mencakup regulasi sediaan farmasi sesuai dengan undang-undang yang berlaku.

Pelayanan kefarmasian telah mengalami perubahan yang semula hanya berfokus kepada pengelolaan obat (drug oriented) berkembang menjadi pelayanan komprehensif (pharmaceutical care) meliputi pelayanan obat dan pelayanan farmasi klinik yang bertujuan untuk meningkatkan kualitas hidup pasien. Menurut Peraturan Menteri Kesehatan Republik Indonesia Nomor 73 Tahun 2016, pelayanan kefarmasian adalah suatu pelayanan langsung dan bertanggung jawab kepada pasien yang berkaitan dengan sediaan farmasi dengan maksud mencapai hasil yang pasti untuk meningkatkan mutu kehidupan pasien (Permenkes RI, 2016). Terdapat beberapa perundang-undangan yang mengatur pelayanan kefarmasian antara lain UU RI Nomor 36 Tahun 2009 Tentang Kesehatan, UU RI Nomor 11 Tahun 2017 Tentang Keselamatan Pasien, PP RI Nomor 51 Tahun 2009 Tentang Pekerjaan Kefarmasian, dan Peraturan Menteri Kesehatan Nomor 73 Tahun 2016 Tentang Standar Pelayanan Kefarmasian di Apotek.

Peran Apoteker dituntut untuk meningkatkan pengetahuan, keterampilan, dan perilaku agar dapat melaksanakan interaksi langsung dengan pasien seperti pemberian informasi obat dan konseling kepada pasien yang membutuhkan. Konseling merupakan proses interaktif antara Apoteker dengan pasien/keluarga untuk meningkatkan pengetahuan, pemahaman, kesadaran dan kepatuhan sehingga terjadi perubahan perilaku dalam penggunaan obat dan menyelesaikan masalah yang dihadapi pasien. Untuk mengawali konseling, Apoteker menggunakan three prime questions. Apabila tingkat kepatuhan pasien dinilai rendah, perlu dilanjutkan dengan metode Health Belief Model. Apoteker harus melakukan verifikasi bahwa pasien atau keluarga pasien sudah memahami obat yang digunakan [3].

Menurut Permenkes RI (2016), terdapat beberapa kriteria pasien/keluarga pasien yang perlu diberi konseling, antara lain: 
1. Pasien kondisi khusus (pediatri, geriatri, gangguan fungsi hati dan/atau ginjal, ibu hamil dan menyusui).

2. Pasien dengan terapi jangka panjang/penyakit kronis (misalnya: TB, DM, AIDS, epilepsi).

3. Pasien yang menggunakan obat dengan instruksi khusus (penggunaan kortikosteroid dengan tappering down/off).

4. Pasien yang menggunakan Obat dengan indeks terapi sempit (digoksin, fenitoin, teofilin).

5. Pasien dengan polifarmasi; pasien menerima beberapa obat untuk indikasi penyakit yang sama. Dalam kelompok ini juga termasuk pemberian lebih dari satu obat untuk penyakit yang diketahui dapat disembuhkan dengan satu jenis obat.

6. Pasien dengan tingkat kepatuhan rendah.

Kemudian, dalam Permenkes RI (2016) juga sudah diatur tahapan dalam memberikan konseling kepada pasien/keluarga pasien, yaitu:

1. Membuka komunikasi antara Apoteker dengan pasien

2. Menilai pemahaman pasien tentang penggunaan obat melalui Three Prime Questions, yaitu:

1) Apa yang disampaikan dokter tentang obat Anda?

2) Apa yang dijelaskan oleh dokter tentang cara pemakaian obat Anda?

3) Apa yang dijelaskan oleh dokter tentang hasil yang diharapkan setelah Anda menerima terapi obat tersebut?

3. Menggali informasi lebih lanjut dengan memberi kesempatan kepada pasien untuk mengeksplorasi masalah penggunaan obat

4. Memberikan penjelasan kepada pasien untuk menyelesaikan masalah penggunaan obat

5. Melakukan verifikasi akhir untuk memastikan pemahaman pasien

Setelah melakukan konseling, Apoteker dapat mendokumentasikan konseling dengan meminta tanda tangan pasien sebagai bukti bahwa pasien memahami informasi yang diberikan dalam konseling. Bukti tersebut dapat berupa formulir yang diisi oleh pasien/keluarga pasien yang mendapatkan konseling dari Apoteker yang bersangkutan [3].

Apoteker berperan penting dalam meningkatkan manajemen obat selama masa perawatan terhadap pasien karena Apoteker memiliki tanggung jawab dalam mengoptimalkan terapi pengobatan pasien [4]. Maka dari itu, Apoteker memiliki potensi untuk memberikan konseling kepada pasien yang artinya proses interaktif antara Apoteker dengan pasien/keluarga dengan tujuan untuk meningkatkan pemahaman, kesadaran, dan kepatuhan sehingga terjadi perubahan perilaku dalam penggunaan obat [5]. Menurut Pedoman Good Pharmacy Practice (GPP), dalam melakukan konseling atau memberikan layanan informasi obat, terdapat beberapa hal yang harus dimiliki dari segi sarana dan 
prasarana antara lain penyediaan area konseling khusus, kelengkapan literature, penjaminan mutu SDM, pembuatan prosedur tetap, dan pendokumentasiannya. Faktor yang harus diperhatikan dalam pemberian konseling di apotek adalah ruangan atau tempat konseling dan alat bantu konseling seperti kartu pasien atau catatan konseling [6].

Selain meningkatkan kepatuhan pasien, manfaat konseling bagi apoteker dan pengembangan apotek adalah mewujudkan bentuk pelayanan asuhan kefarmasian sebagai tanggung jawab profesi apoteker, menjaga citra profesi sebagai bagian dari tim pelayanan kesehatan, dan menjadi pelayanan tambahan untuk menarik pelanggan sehingga menjadi upaya pemasaran jasa pelayanan [7].

Penelitian ini bertujuan untuk mengetahui pelaksanaan konseling obat oleh Apoteker kepada pasien di Apotek sesuai dengan Peraturan Menteri Kesehatan Nomor 73 Tahun 2016. Objek dalam penelitian ini adalah Apotek yang berada di wilayah Kabupaten Badung, Provinsi Bali.

\section{METODE PENELITIAN \\ Bahan dan Peralatan}

Kumpulan data pada penelitian ini meliputi data apotek, data apoteker, dan pelaksanaan konseling di apotek oleh apoteker di Kabupaten Badung, Provinsi Bali.

\section{Metode}

Penelitian ini adalah penelitian non eksperimental dengan rancangan cross sectional yaitu mengumpulkan data tentang pelaksanaan konseling kepada pasien di apotek-apotek kabupaten Badung dalam waktu bersamaan. Rancangan cross sectional ialah penelitian yang mendesain pengumpulan datanya dilakukan pada satu titik waktu (at one point in time) yang mana fenomena yang diteliti adalah selama satu periode pengumpulan data. Dalam penelitian ini data diambil dengan menyebarkan kuesioner melalui google form. Pengisian google form oleh Apoteker Pengelola Apotek (APA) di kabupaten Badung. Data yang diperoleh dianalisis dan selanjutnya dibuat persentasenya.

\section{HASIL DAN PEMBAHASAN}

Penelitian ini dilakukan dengan cara menyebarkan kuesioner melalui google form secara online kepada Apoteker yang bekerja di Apotek Kabupaten Badung. Jumlah responden yang mengisi kuesioner ini sebanyak 18 responden. Berikut ini akan dibahas data apotek, data apoteker, dan data pelaksanaan konseling.

\section{Data Apotek}

Berdasarkan Tabel 1., 12 apotek $(66,67 \%)$ berdiri selama 3-5 tahun sedangkan $6(33,33 \%)$ apotek sudah berdiri selama lebih dari 5 tahun. Terdapat 12 apotek $(66,67 \%)$ yang dimiliki oleh apoteker, 2 apotek $(11,11 \%)$ yang dimiliki oleh non-apoteker, dan 4 apotek $(22,22 \%)$ yang dimiliki oleh kerjasama antara apoteker dan nonapoteker. Sebanyak 10 apotek $(55,55 \%)$ yang buka di Kabupaten Badung selama lebih dari 12 jam dan hanya 8 apotek $(44,44 \%)$ yang buka selama kurang dari 12 jam. Jumlah rata-rata resep yang dilayani oleh responden per harinya yang 
kurang dari 10 resep per hari sebanyak 12 responden $(66,67 \%)$ sedangkan yang lebih dari 10 resep per hari hanya 6 responden $(33,33 \%)$. Apotek yang memiliki praktek dokter hanya 8 apotek $(44,44 \%)$ dari 18 apotek yang mengisi kuesioner. Jumlah tenaga teknis kefarmasian yang terdapat di masing-masing apotek berkisar 1-5 orang. Berdasarkan data apotek tersebut, hal yang diatur dalam PP
No. 51 Tahun 2009 Tentang Pekerjaan Kefarmasian [8] adalah kepemilikan apotek yang mana apotek dapat didirikan oleh apoteker maupun non-apoteker asalkan pekerjaan kefarmasian harus dilakukan oleh apoteker yang bersangkutan. Selain itu, di setiap apotek yang berada di Kabupaten Badung sudah terdapat tenaga kefarmasian meliputi apoteker dan tenaga teknis kefarmasian.

Tabel 1. Data Apotek

\begin{tabular}{|c|c|c|}
\hline Data Apotek & $\begin{array}{c}\text { Jumlah } \\
\text { Responden }\end{array}$ & Persentase \\
\hline \multicolumn{3}{|l|}{ Lama Apotek berdiri } \\
\hline - 3-5 tahun & 12 & $66,67 \%$ \\
\hline$->5$ tahun & 6 & $33,33 \%$ \\
\hline \multicolumn{3}{|l|}{ Pemilik Apotek } \\
\hline - Perorangan: Apoteker & 12 & $66,67 \%$ \\
\hline - Perorangan: Non-Apoteker & 2 & $11,11 \%$ \\
\hline - Kerjasama & 4 & $22,22 \%$ \\
\hline \multicolumn{3}{|l|}{ Jam Buka Apotek } \\
\hline$-\quad<12$ jam & 8 & $44,44 \%$ \\
\hline$-\quad>12 \mathrm{jam}$ & 10 & $55,55 \%$ \\
\hline \multicolumn{3}{|l|}{ Jumlah Rata-Rata Resep } \\
\hline$-\quad<10 \mathrm{resep} / \mathrm{hari}$ & 12 & $66,67 \%$ \\
\hline - $\quad>10 \mathrm{resep} / \mathrm{hari}$ & 6 & $33,33 \%$ \\
\hline \multicolumn{3}{|l|}{ Apotek ada Praktek Dokter } \\
\hline$-\quad \mathrm{Ya}$ & 8 & $44,44 \%$ \\
\hline - $\quad$ Tidak & 10 & $55,55 \%$ \\
\hline \multicolumn{3}{|l|}{ Jumlah Tenaga Teknis } \\
\hline Kefarmasian & & $44,44 \%$ \\
\hline - $\quad 1-2$ orang & $\begin{array}{l}0 \\
8\end{array}$ & $44,44 \%$ \\
\hline - $\quad 3-5$ orang & $\begin{array}{l}8 \\
2\end{array}$ & $11,11 \%$ \\
\hline$-\quad>5$ orang & & \\
\hline
\end{tabular}

2. Data Apoteker

Sebanyak 10 responden $(55,55 \%)$ yang bekerja di apotek Kabupaten Badung berjenis kelamin laki-laki sedangkan hanya 8 apoteker $(44,44 \%)$ yang berjenis kelamin perempuan dengan usia responden yang berusia 20-30 tahun sebanyak 8 
orang $(44,44 \%)$, usia $30-40$ tahun sebanyak 4 orang $(22,22 \%)$, dan usia yang lebih dari 40 tahun sebanyak 6 orang $(33,33 \%)$. Dari segi lama pengalaman kerja di apotek, apoteker yang bekerja di apotek Kabupaten Badung memiliki pengalaman kerja diatas 1 tahun. Terdapat 10 responden $(55,55 \%)$ yang bekerja di apotek datang setiap hari, 6 responden $(33,33 \%) \quad$ datang seminggu 3-5 kali, dan hanya 2 responden $\quad(11,11 \%) \quad$ datang seminggu 1-2 kali. Namun, frekuensi kehadiran apoteker di apotek seharusnya lebih ditingkatkan agar tercapainya suatu pelayanan kefarmasian yang baik. Rata-rata lama apoteker tiap kali datang ke apotek sudah lebih dari 1 jam. Berdasarkan hal tersebut, apoteker yang bekerja di apotek Kabupaten Badung sudah menjalankan tugasnya dengan cukup baik dengan memiliki pengalaman kerja yang baik.

Tabel 2. Data Apoteker

\begin{tabular}{ccc}
\hline \multicolumn{1}{c}{ Data Apoteker } & $\begin{array}{c}\text { Jumlah } \\
\text { Responden }\end{array}$ & Persentase \\
\hline Jenis Kelamin & 10 & \\
- Laki-laki & 8 & $55,55 \%$ \\
- Perempuan & & $44,44 \%$ \\
\hline Usia Apoteker & 8 & $44,44 \%$ \\
- 20-30 Tahun & 4 & $22,22 \%$ \\
- 30-40 Tahun & 6 & $33,33 \%$ \\
- > 40 Tahun & & \\
Lama Pengalaman Kerja di Apotek & 0 & $0 \%$ \\
- $\quad$ 1 Tahun & 6 & $33,33 \%$ \\
- 1-5 Tahun & 8 & $44,44 \%$ \\
- 6-10 Tahun & 4 & $22,22 \%$ \\
\hline Frekuensi Kehadiran Apoteker & & \\
- Sebulan sekali & 0 & $0 \%$ \\
- Sebulan dua kali & 0 & $0 \%$ \\
- Seminggu 1-2 kali & 2 & $11,11 \%$ \\
- Seminggu 3-5 kali & 6 & $33,33 \%$ \\
- Setiap hari & 10 & $55,55 \%$ \\
\hline Lama Tiap Kali Datang ke Apotek & & \\
- < 1 jam & 0 & $0 \%$ \\
- 1-3 jam & 4 & $22,22 \%$ \\
- 3-6 jam & 8 & $44,44 \%$ \\
- > 6 jam & 6 & $33,33 \%$ \\
\hline
\end{tabular}

3. Data Pelaksanaan Konseling

Sebanyak $100 \%$ responden menyatakan bahwa konseling obat penting dilakukan kepada pasien untuk meningkatkan kepatuhan pasien dalam minum obat. Tujuan lainnya adalah untuk mendapatkan kepuasan, mencegah bahaya penggunaan obat, sebagai strategi bisnis, dan untuk meningkatkan penjualan. Sebanyak $55,55 \%$ sadar bahwa apoteker wajib memberikan konseling kepada pasien karena hal tersebut sudah tugas apoteker. 
Tabel 3. Data Alasan Konseling

\begin{tabular}{lcc}
\hline \multicolumn{1}{c}{ Alasan } & $\begin{array}{c}\text { Jumlah } \\
\text { Responden }\end{array}$ & Persentase \\
\hline Untuk meningkatkan kepatuhan pasien & 18 & $100 \%$ \\
Untuk mendapatkan kepuasan & 10 & $55,55 \%$ \\
Karena sudah sebagai tugas Apoteker & 10 & $55,55 \%$ \\
memberikan konseling & 4 & $22,22 \%$ \\
Untuk meningkatkan penjualan & 8 & $44,44 \%$ \\
Sebagai strategi bisnis & 10 & $55,55 \%$ \\
Mencegah bahaya penggunaan obat & & \\
\hline
\end{tabular}

Dari 18 responden, sebanyak $100 \%$ responden pernah melakukan konseling kepada pasien dengan durasi yang bervariasi. Sebanyak 8 responden melakukan konseling kurang dari 5 menit, 6 responden selama 5-10 menit, dan 4 responden selama 10-15 menit. Tidak ada responden yang melakukan konseling diatas 15 menit. Waktu ideal dalam melakukan konseling pasien sebaiknya 5-10 menit agar informasi yang diperlukan pasien dapat tersampaikan dengan baik. Menurut Lutfiyati dkk. (2016), semua apoteker seharusnya memberikan konseling kepada pasien agar mengetahui kondisi pasien, informasi yang dibutuhkan pasien, dan meningkatkan pengetahuan pasien. Namun, terdapat beberapa hambatan apoteker saat melakukan konseling yaitu kurangnya waktu, pengetahuan, dan tempat. Sebanyak $44,44 \%$ mengaku bahwa waktu konseling kurang karena terdapat beberapa pasien yang cenderung terburu-buru membeli obat sehingga apoteker tidak bisa memberikan konseling. Sebanyak 33,33\% mengaku bahwa pengetahuan dan tempat yang kurang juga menjadi kendala sebagai apoteker dalam memberikan konseling. Maka dari itu, apoteker dituntut untuk aktif dalam mencari informasi dan mengikuti seminar, workshop, dan pelatihan [9]. Selain itu, menurut Abdullah dkk. (2010), ruangan konseling bagi pasien harus dilengkapi dengan meja dan kursi serta lemari untuk menyimpan catatan medikasi pasien. Tetapi, sebanyak $44,44 \%$ responden mengaku bahwa tidak ada hambatan dalam pemberian konseling obat di apotek.

Tabel 4. Lama Melakukan Konseling

\begin{tabular}{ccc}
\hline $\begin{array}{c}\text { Lama melakukan } \\
\text { Konseling }\end{array}$ & $\begin{array}{c}\text { Jumlah } \\
\text { Responden }\end{array}$ & Persentase \\
\hline < 5 Menit & 8 & $44,44 \%$ \\
5-10 Menit & 6 & $33,33 \%$ \\
10-15 Menit & 4 & $22,22 \%$ \\
$>15$ Menit & 0 & $0 \%$ \\
\hline
\end{tabular}


Tabel 5. Hambatan Konseling

\begin{tabular}{lcc}
\hline Hambatan Konseling & $\begin{array}{c}\text { Jumlah } \\
\text { Responden }\end{array}$ & Persentase \\
\hline Waktu kurang & 8 & $44,44 \%$ \\
Pengetahuan kurang & 6 & $33,33 \%$ \\
Tempat kurang & 6 & $33,33 \%$ \\
Tidak ada hambatan & 8 & $44,44 \%$ \\
\hline
\end{tabular}

Informasi yang disampaikan oleh apoteker dalam melakukan konseling obat antara lain penyimpanan obat $(100 \%)$, cara penggunaan obat $(100 \%)$, waktu penggunaan obat $(88,88 \%)$, lama penggunaan obat $(88,88 \%)$, dosis obat $(77,77 \%)$, dan efek samping obat $(66,67 \%)$. Kebutuhan pasien terhadap informasi obat meliputi nama generik, nama obat yang sejenis, indikasi, bentuk sediaan obat, dosis, aturan pemakaian, cara penyimpanan yang tepat, efek samping. Interaksi obat dengan obat / makanan / alkohol, informasi tentang pengulangan obat resep, informasi khusus obat tertentu, harga obat sejenis yang lebih murah dan terjangkau [10].

Tabel 6. Informasi yang Disampaikan

\begin{tabular}{lcc}
\hline Informasi yang Disampaikan & $\begin{array}{c}\text { Jumlah } \\
\text { Responden }\end{array}$ & Persentase \\
\hline Dosis obat & 14 & $77,78 \%$ \\
Waktu penggunaan obat & 16 & $88,89 \%$ \\
Efek samping obat & 12 & $66,67 \%$ \\
Lama penggunaan obat & 16 & $77,78 \%$ \\
Penyimpanan obat & 18 & $100 \%$ \\
Cara penggunaan obat & 18 & $100 \%$ \\
\hline
\end{tabular}

Terdapat 14 responden $(77,78 \%)$ yang tidak melakukan pendokumentasian konseling obat. Hal ini dapat terjadi karena keterbatasan waktu apoteker yang merangkap pula menjadi tenaga administrasi [9]. Menurut Permenkes RI (2016), kegiatan dalam konseling meliputi membuka komunikasi antar apoteker dengan pasien, mengidentifikasi tingkat pemahaman pasien tentang penggunaan obat, memberikan penjelasan kepada pasien, meakukan verifikasi akhir dalam rangka mengecek pemahaman pasien, dan dokumentasi konseling. Dokumentasi konseling meliputi pengisian formulir yang ditandatangai oleh pasien. Selain itu, dari 18 responden, 10 responden $(55,56 \%)$ tidak melakukan pencatatan pengobatan pasien.

Sebanyak $100 \%$ responden berharap bahwa kepatuhan pasien akan meningkat jika diberikan konseling obat oleh apoteker. Pelayanan informasi mengenai obat sebagai salah satu metode edukasi 

$\begin{array}{lllr}\text { pengobatan } & \text { secara tatap muka } \\ \text { merupakan } & \text { salah satu bentuk }\end{array}$ pelayanan kefarmasian yang berguna untuk meningkatkan pengetahuan dan kepatuhan pasien dalam minum obat [10]. Menurut Notoatmodjo (1991), salah satu faktor yang berhubungan dengan kepatuhan seseorang adalah penyuluhan langsung perorangan sebagai faktor untuk meningkatkan pengetahuan dan membentuk sikap yang positif [11].

Tabel 7. Harapan Dilaksanakannya Konseling

\begin{tabular}{lcc}
\hline \multicolumn{1}{c}{$\begin{array}{c}\text { Harapan Dilaksanakannya } \\
\text { Konseling }\end{array}$} & $\begin{array}{c}\text { Jumlah } \\
\text { Responden }\end{array}$ & Persentase \\
\hline Kepatuhan pasien meningkat & 18 & $100 \%$ \\
Mendapatkan kepuasan & 8 & $44,44 \%$ \\
Penjualan meningkat & 8 & $44,44 \%$ \\
\hline
\end{tabular}

Sebanyak 16 responden $(88,89 \%)$ mengetahui bahwa ada peraturan perundang-undangan yang mengatur bahwa apoteker harus melakukan konseling kepada pasien tertentu. Terdapat berbagai peraturan perundang-undangan yang mengatur kinerja pelayanan kefarmasian seperti PP No. 51 Tahun 2009 Tentang Pekerjaan Kefarmasian dan Permenkes RI No. 73 Tahun 2016 Tentang Standar Pelayanan Kefarmasian di Apotek. Konseling tidak dilakukan kepada semua pasien tetapi hanya pada pasien dengan kondisi tertentu seperti pasien dengan kondisi khusus (pediatri, geriatri, gangguan fungsi hati dan/atau ginjal, ibu hamil dan menyusui), pasien dengan terapi jangka panjang/penyakit kronis (misalnya: TB, DM, AIDS, epilepsi), pasien yang menggunakan obat dengan instruksi khusus, dan pasien dengan tingkat kepatuhan yang rendah. Maka dari itu, walaupun sebanyak $100 \%$ responden melakukan konseling, namun harus diperhatikan pula keadaan pasien.

\section{KESIMPULAN}

Berdasarkan data yang diperoleh, sebanyak $100 \%$ responden pernah melaksanakan konseling kepada pasien dengan rentang waktu yang bervariasi. Responden sudah melakukan konseling dalam rentang waktu 1-10 menit. Pada saat pemberian konseling, sebanyak $55,55 \%$ responden mengaku bahwa terdapat hambatan dalam pemberian konseling seperti waktu, tempat, dan pengetahuan yang kurang. Pemberian informasi dalam pelaksanaan konseling yaitu cara penggunaan dan penyimanan obat $(100 \%)$, waktu penggunaan obat $(88,89 \%)$, dosis obat dan lama penggunaan obat $(77,78 \%)$, serta efek samping obat $(66,67 \%)$. Hal ini sudah cukup baik untuk meningkatkan kepatuhan pasien dalam mengonsumsi obat. Namun, pendokumentasian konseling dan pencatatan riwayat pasien masih belum efektif dalam pelaksanaannya karena berbagai faktor. Dari segi pengetahuan apoteker terkait perundang-undangan yang mengatur kinerja tenaga 
kefarmasian, sebanyak $88,89 \%$ responden sudah mengetahui hal tersebut. Maka dari itu, diharapkan apoteker dapat melaksanakan tugasnya dengan baik sesuai dengan peraturan perundang-undangan.

\section{UCAPAN TERIMA KASIH}

Pada kesempatan ini, penulis mengucapkan terimakasih kepada pihak apotek di Kabupaten Badung atas kesempatan yang diberikan hingga terselesaikannya penelitian ini.

\section{DAFTAR PUSTAKA}

[1] Wirasuta, M.A.G. 2008. Analisis Toksikologi Forensik dan Interpretasi Temuan Analisis. Indonesian Journal of Legal and Forensic Sciences. 1(1): 47-55.

[2] Anderson, P.D. 2012. The Broad Field of Forensic Pharmacy. Journal of Pharmacy Practice. 25(1): 7-12.

[3] Permenkes RI. 2016. Peraturan Pemerintah Republik Indonesia Nomor 73 Tahun 2016 Tentang Standar Palayanan Kefarmasian di Apotek. Jakarta: Peraturan Pemerintah Republik Indonesia.

[4] Nwaozuzu, E. E., Okonta, J. M., and Nze, C. 2013. Pharmaceutical Care Interventions, Their Outcomes and Patients Satisfaction in Antiretroviral Drug Therapy. International Journal of Development and Sustainability. 2: 430-444.

[5] Sanii, Y., Torkamandi, H., Gholami, K., Hadavand, N., \& Javadi, M. 2016. Role Of Pharmacist Counseling In
Pharmacotherapy Quality Improvement. Journal Of Research In Pharmacy Practice. 5(2): 132.

[6] Kemenkes RI. 2011. Pedoman Cara Pelayanan Kefarmasian yang Baik (CPFB). Jakarta: Kementerian Kesehatan Republik Indonesia dan Pengurus Pusat Ikatan Apoteker Indonesia.

[7] Departemen Kesehatan RI. 2007. Pedoman Konseling Pelayanan Kefarmasian di Sarana Kesehatan. Jakarta: Direktorat Bina Farmasi Komunitas dan Klinik Direktorat Jenderal Bina Kefarmasian dan Alat Kesehatan.

[8] Anonim. 2009. Peraturan Pemerintah Republik Indonesia Nomor 51 Tahun 2009 Tentang Pekerjaan Kefarmasian. Jakarta: Peraturan Pemerintah Republik Indonesia.

[9] Lutfiyati, H., F. Yuliastuti, dan P.S. Diantia. 2016. Pelaksanaan Konseling Oleh Apoteker di Apotek Kecamatan Temanggung. Jurnal Farmasi Sains dan Praktis. 2(1): 24-30.

[10] Abdullah, N.A., R. Andrajati, dan S. Supardi. 2010. Pengetahuan, Sikap, dan Kebutuhan Pengunjung Apotek Terhadap Informasi Obat di Kota Depok. Buletin Penelitian Sistem Kesehatan. 13(4): 344352.

[11] Notoatmodjo, S. 1991. Pengantar Perilaku Kesehatan. Jurusan Pendidikan dan Ilmu Pengetahuan, Fakultas Kesehatan Masyarakat Universitas Indonesia, Depok. 